\title{
Diagnostic performance of DNA microarray for detecting rifampicin and isoniazid resistance in Mycobacterium tuberculosis
}

\author{
Bingqi Sun ${ }^{1}$, Ying Sun ${ }^{2}$ \\ ${ }^{1}$ Department of Laboratory Medicine, No. 10 People's Hospital of Shenyang, Shenyang, China; ${ }^{2}$ Department of Oncology, No. 10 People's Hospital \\ of Shenyang, Shenyang, China \\ Contributions: (I) Conception and design: Both authors; (II) Administrative support: Y Sun; (III) Provision of study materials or patients: B Sun; \\ (IV) Collection and assembly of data: B Sun; (V) Data analysis and interpretation: Both authors; (VI) Manuscript writing: Both authors; (VII) Final \\ approval of manuscript: All authors. \\ Correspondence to: Ying Sun. No. 10 People's Hospital of Shenyang, Shenyang 110044, China. Email: ChesthospJYK@163.com.
}

Background: While rifampicin (RFP) and isoniazid (INH) are the most commonly used first-line antituberculosis drugs, multidrug resistance in Mycobacterium tuberculosis poses a threat to the success of tuberculosis (TB) control programs. Clinical practice guidelines and expert consensuses recommend drug susceptibility testing (DST) before the initiation of antituberculosis treatment. However, traditional DST is time-consuming and has high requirements for laboratory conditions. The recently developed molecular diagnostic techniques, such as DNA microarray, offer new options. We thus investigated the diagnostic value of DNA microarray in detecting RFP + INH-resistant TB, with an attempt to identify simple, efficient, and accurate drug-resistant TB testing methods.

Methods: The clinical features and DST results of patients diagnosed with pulmonary tuberculosis by Bactec MGIT 960 liquid culture system (Becton, Dickinson and Company, Franklin Lakes, NJ, USA) who received DNA microarray analysis in our center from July 2019 to July 2020 were retrospectively analyzed. Level of agreement between liquid culture and DNA microarray technology was assessed by using the Cohen kappa coefficient. With the results of liquid culture as the gold standard, the sensitivity and specificity of the DNA microarray were calculated, and the receiver operating characteristic (ROC) curves were used to assess the diagnostic values of the DNA microarray in detecting RFP + INH-resistant TB.

Results: A total of 825 patients were enrolled. The sensitivity and specificity of DNA microarray were 0.84 and 0.94, respectively, in the detection of RFP resistance, with an area under the curve (AUC) of 0.89 [95\% confidence interval (CI): 0.87-0.91)] and a Cohen kappa coefficient of 0.78 (95\% CI: 0.72-0.83). For INH resistance, the sensitivity and specificity of the DNA microarray were 0.73 and 0.97 , respectively, with an AUC of 0.85 (95\% CI: 0.82-0.87) and a Cohen kappa coefficient of 0.75 (95\% CI: 0.70-0.80).

Conclusions: The DNA microarray had high specificity and sensitivity in detecting RFP + INH-resistant TB. As a rapid, accurate, and practical technique, it can be routinely performed in clinical laboratories.

Keywords: Mycobacterium tuberculosis; drug resistance; rifampicin; isoniazid; DNA microarray

Submitted Apr 30, 2021. Accepted for publication Jul 06, 2021.

doi: $10.21037 /$ jtd-21-913

View this article at: https://dx.doi.org/10.21037/jtd-21-913

(c) Journal of Thoracic Disease. All rights reserved. 


\section{Introduction}

According to the World Health Organization (WHO), an estimated 10 million tuberculosis (TB) cases occur worldwide every year, with China accounting for $9 \%$ of the total annual incidence. Although the number of TB deaths is declining globally, it remains one of the top 10 causes of death worldwide (1). While rifampicin (RFP) and isoniazid (INH) are the most commonly used first-line anti-TB drugs, multidrug resistance (MDR) in Mycobacterium tuberculosis poses a great threat to the success of TB treatment and global TB control $(2,3)$. It was reported that $4.1 \%$ of all newly diagnosed and $19.0 \%$ of all previously treated TB patients are RFP-resistant; globally the total number of RFP-resistant TB patients reached 600,000, among whom 490,000 (82\%) had MDR (i.e., resistance to at least RFP and INH) (1). Both the updated WHO guidelines for the treatment of multidrug- and rifampicin-resistant TB (MDR/ RR-TB) and the 2019 WHO Consolidated Guidelines on DrugResistant Tuberculosis Treatment recommend phenotypic drug susceptibility testing (DST) prior to anti-TB treatment, which should be applied for first- and second-line antiTB drugs, with rapid molecular DST being performed whenever possible $(4,5)$. Currently, the WHO recommends $M$. tuberculosis culture as the reference standard for drug resistance testing; however, the traditional method is timeconsuming (7-12 weeks) and has high technical laboratory requirements (6). Delays in DST may lead to prolonged use of ineffective drugs and missed opportunities to prevent transmission (7). With the development of testing technologies, drug resistance in M. tuberculosis can now successfully be detected by several molecular techniques, including real-time quantitative polymerase chain reaction (RT-PCR) (Xpert MTB/RFP) (8), line probe assays (LPAs) (9), and DNA microarray (10). DNA microarray uses specific genes at specific nucleotide sites to determine resistance to RFP and/or INH by detecting mutations in $M$. tuberculosis robB, kat $G$, and $i n h A$ genes (11). Compared with other molecular techniques, DNA microarray is simpler and more affordable; also, it enables the simultaneous detection of both INH and RFP resistance-associated mutations in M. tuberculosis (12). Here, we investigated the diagnostic performance of DNA microarray in detecting RFP + INHresistant $\mathrm{TB}$, with an attempt to identify simple, efficient, and accurate drug-resistant TB testing methods. We hypothesized that the DNA microarray would have the same detection performance compared with traditional culture methods. We present the following article in accordance with the STARD reporting checklist (available at https://dx.doi.org/10.21037/jtd-21-913).

\section{Methods}

\section{Participants}

In this retrospective study, patients with suspected TB admitted to our center from July 2019 to July 2020 were enrolled as the research participants. The inclusion criteria were as follows: (I) the diagnosis of pulmonary TB was confirmed by sputum mycobacterium culture; and (II) the same specimen was tested for both RFP and INH resistance with DNA microarray. The exclusion criteria were as follows: (I) contaminated specimens, and/or (II) lack of key data. All procedures performed in this study involving human participants were in accordance with the Declaration of Helsinki (as revised in 2013). All patients signed the informed consent forms, and the study was approved by the institutional review board of our hospital (Ethical approval document number: KYXM-2019-056-01).

\section{Equipment and reagents}

Bactec MGIT960 liquid culture system and reagents (BD, Becton, Dickinson and Company, Franklin Lakes, NJ, USA) were used for liquid culture, with the reagent lot number being 9234016 and the DST reagent lot number being 9296422. Microarray hybridization was based on CapitalBio DNA microarray (CapitalBio Corp., Beijing, China).

\section{Assays}

\section{Traditional liquid culture method}

The Bactec MGIT960 system was used for rapid culture and DST, as described in a Chinese TB laboratory test protocol (13). More specifically, $0.5 \mathrm{~mL}$ of the treated specimen was added into a mycobacteria growth indicator tube (MGIT), which was then placed on the Bactec MGIT960 liquid culture system for culture. Positive specimens were further used for DST. During DST, $M$. tuberculosis isolated from TB patients was subject to in vitro culture in known concentrations of the test drugs, with a final concentration of $1.0 \mu \mathrm{g} / \mathrm{mL}$ for RFP and $0.1 \mu \mathrm{g} / \mathrm{mL}$ for INH in the culture tubes. The results of DST were reported automatically by the Bactec MGIT960 system on days 4-13.

\section{Microarray analysis}

The RFP resistance gene $r p o B$ and the INH resistance 


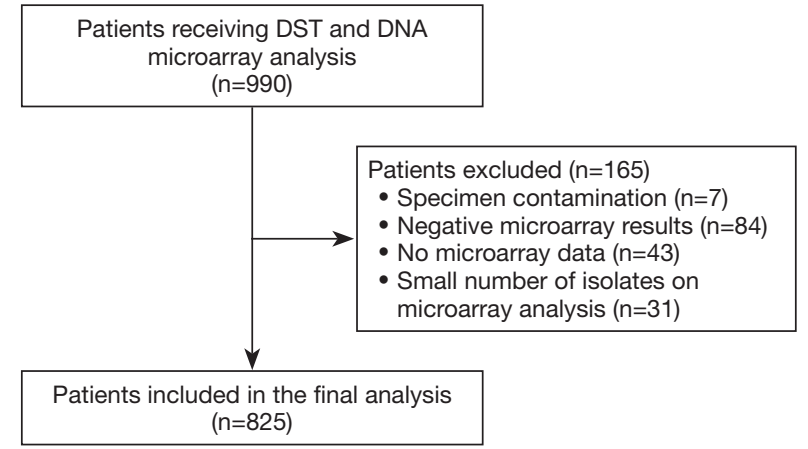

Figure 1 Flow chart of patient enrollment. DST, drug susceptibility testing.

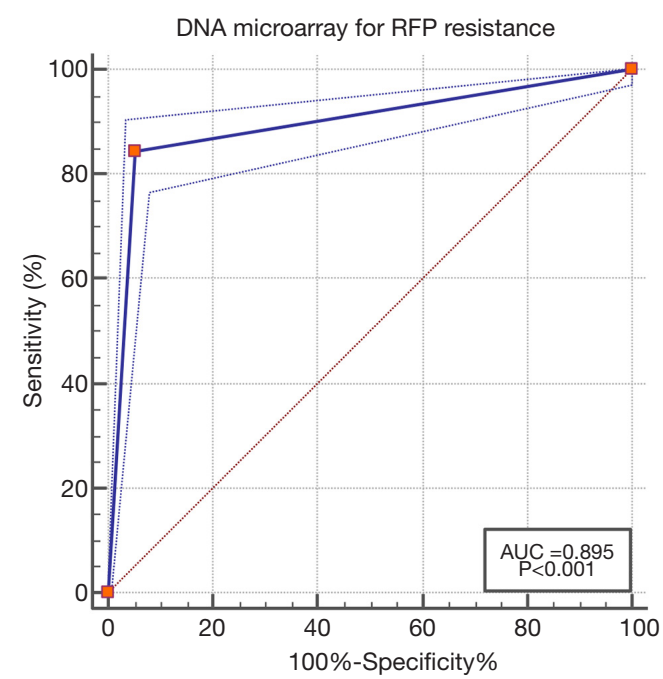

Figure 2 The ROC curve of the CapitalBio DNA microarray for detecting RFP resistance. ROC, receiver operating characteristic; RFP, rifampicin.

genes $k a t G$ and $i n h A$ were used as target genes. The wild type and mutations of these genes in M. tuberculosis were detected. The specimens were stored in appropriate sterile containers. During the test, mixed phosphate buffer $(\mathrm{pH}$ 6.8) was added 15-20 minutes after incubation in 4\% $\mathrm{NaOH}$, and the subsequent mixture was stirred 1-2 times. The supernatant was removed following centrifugation, the pellet was washed with $0.5-1 \mathrm{~mL}$ of mixed phosphate buffer, and the resultant sediments were placed on the microarray platforms. The results were recorded by a LuxScan $10 \mathrm{~K}$ microarray scanner (CapitalBio). PCR, hybridization, washing/drying, scanning, and result interpretation were performed according to the manufacturer's instructions.

\section{Statistical analysis}

The results of the conventional culture method were used as the gold standard to evaluate the detection performance of the DNA microarray, and the detection results were transformed, with 0 indicating sensitive and 1 indicating resistant. The differences and agreements in testing results between the 2 methods were evaluated by using the McNemar test and Cohen's kappa, respectively. Kappa values below 0.4 indicated poor agreement, values between 0.4 and 0.75 indicated fair agreement, and values of 0.75 and higher indicated good and excellent agreement. The receiver operating characteristic (ROC) curves were used to calculate the specificity, sensitivity, and area under the curve (AUC) of the DNA microarray. The sensitivity and specificity were determined by the maximum value of the Youden Index. A P value $<0.05$ was deemed statistical significant. All statistical analyses were performed using MedCalc 19.0.4 software (MedCalc, Mariakerke, Belgium).

\section{Results}

\section{Patients}

DST was performed in a total of 990 patients during the study period. After 165 patients were excluded (including specimen contamination in 7 cases, negative microarray results in 84 cases, no microarray data in 43 cases, and a small number of isolates on microarray analysis in 31 cases), 825 patients (including 592 treatment-naive patients and 233 patients seeking retreatment) were entered into the final analysis. The patient inclusion flow chart is shown in Figure 1.

\section{Diagnostic performance of DNA microarray for RFP resistance}

Among the 825 patients, 181 were RFP resistant (as detected by liquid culture), with 153 of these being detected by DNA microarray; 644 were RFP sensitive, with 609 of these being detected by DNA microarray. The difference in value between liquid culture and DNA microarray was -0.85 (95\% CI: -2.73 to $1.04 ; \mathrm{P}=0.45$ ). For the detection of RFP resistance, the sensitivity and specificity of the DNA microarray were 0.84 and 0.94 , respectively, with an AUC of 0.89 (95\% CI: 0.87-0.91; Figure 2). The kappa coefficient between the DNA microarray and liquid culture was 0.78 (95\% CI: 0.72-0.83; Table 1). 
Table 1 Diagnostic performance of DNA microarray for RFP resistance

\begin{tabular}{|c|c|c|c|c|c|c|c|c|c|c|}
\hline $\begin{array}{l}\text { Detection } \\
\text { method }\end{array}$ & Results & \multicolumn{2}{|c|}{ Traditional liquid culture } & $\mathrm{Se}$ & Spe & AUC (95\% Cl) & $\mathrm{P}$ & $\begin{array}{l}\text { Difference value } \\
(95 \% \mathrm{Cl}, \%)\end{array}$ & $\mathrm{P}$ & Kappa (95\% Cl) \\
\hline \multirow{2}{*}{$\begin{array}{l}\text { DNA } \\
\text { microarray }\end{array}$} & Sensitive & 609 & 28 & \multirow[b]{2}{*}{$84.5 \%$} & \multirow[b]{2}{*}{$94.5 \%$} & \multirow[b]{2}{*}{$0.89(0.87-0.91)$} & \multirow[b]{2}{*}{$<0.001$} & \multirow[b]{2}{*}{$-0.85(-2.73$ to 1.04$)$} & \multirow[b]{2}{*}{0.45} & \multirow[b]{2}{*}{$0.78(0.72-0.83)$} \\
\hline & Resistant & 35 & 153 & & & & & & & \\
\hline
\end{tabular}

AUC, area under the curve; Cl, confidential interval; RFP, rifampicin; Se, sensitivity; Spe, specificity.

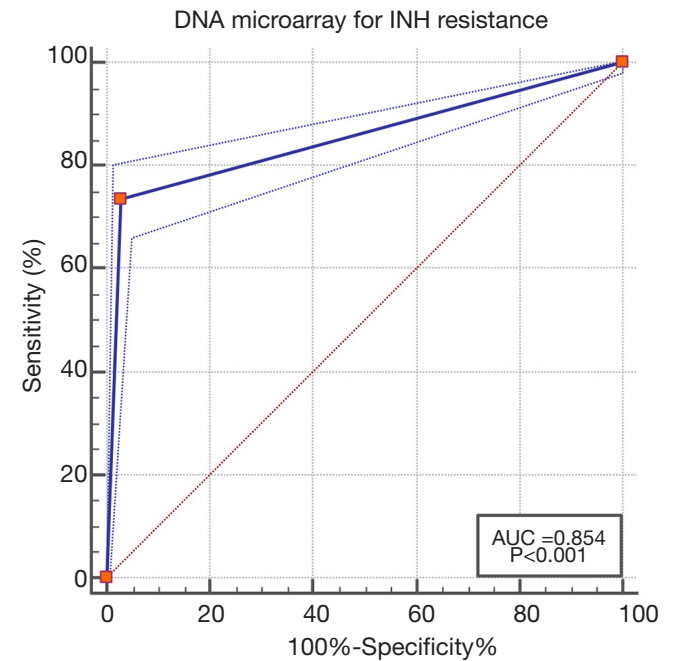

Figure 3 The ROC curve of the CapitalBio DNA microarray for detecting INH resistance. ROC, receiver operating characteristic; IHN, isonicotinic acid hydrazide.

\section{Diagnostic performance of DNA microarray for INH resistance}

Among the 825 patients, 250 were INH resistant, with 184 of these being detected by DNA microarray; 575 were INH sensitive, with 559 of these being detected by DNA microarray. The difference in value between liquid culture and DNA microarray was 6.06 (95\% CI: 3.95-8.17; $\mathrm{P}<0.001$ ). For the detection of RFP resistance, the sensitivity and specificity of DNA microarray were 0.73 and 0.97 , respectively, with an AUC of 0.85 (95\% CI: 0.82-0.87; Figure 3). The kappa coefficient between the DNA microarray and the liquid culture was 0.75 (95\% CI: 0.70-0.80; Table 2).

\section{Discussion}

In our current study, gene microarray technology was used to detect the resistance to RFP and/or INH in 825 pulmonary TB patients, with the traditional liquid culture method as the reference standard. The results showed that the gene microarray technology had good diagnostic performance for drug resistance in $M$. tuberculosis, and its detection results were in good agreement with those of the traditional method. Compared with the traditional method, the gene microarray technology is a simple, affordable, and reliable technique in clinical practice.

\section{Recent research advances}

\section{Detection of RFP-resistant M. tuberculosis with DNA} microarray

In 1999, Head et al. (14) attempted to use gene microarray technology to detect $M$. tuberculosis rifampicin resistance; they performed primer extension-based sequence scanning of the $r p o B$ gene of $M$. tuberculosis and identified RFPresistant clinical isolates. In 2001, Jing et al. (15) used gene microarray technology to detect $M$. tuberculosis resistance to RFP, and the specificity and sensitivity of the technique were high (with a detection efficiency of $83 \%$ ). Gene microarray technology has been widely adopted by clinical laboratories thereafter (16-20). A meta-analysis (including 15 studies) in 2014 showed that the overall sensitivity of DNA microarray for detecting RFP resistance was 0.91 (95\% CI: 0.89-0.92), the overall specificity was 0.96 (95\% CI: $0.96-0.97$ ), and the AUC was 0.97 (21). A recently published study by Zhang et al. (22) showed that the sensitivity and specificity of DNA microarray for detecting RFP resistance in patients with previously treated TB were $83.1 \%$ and $98.7 \%$, respectively. Our results were consistent with the findings of previous studies. These evidences indicated that gene microarray technology is accurate and reliable and can be used to detect drug-resistant mutations of $M$. tuberculosis in clinical practice. In addition, compared with traditional liquid culture methods, gene microarray technology has the advantages of faster, simpler, and cheaper.

\section{Detection of INH-resistant $M$. tuberculosis with DNA microarray \\ In 2004, Cui et al. (17) applied DNA microarray to detect}


Table 2 Diagnostic performance of DNA microarray for INH resistance

\begin{tabular}{|c|c|c|c|c|c|c|c|c|c|c|}
\hline \multirow{2}{*}{$\begin{array}{l}\text { Detection } \\
\text { method }\end{array}$} & \multirow[t]{2}{*}{ Results } & \multicolumn{2}{|c|}{$\begin{array}{c}\text { Traditional liquid } \\
\text { culture }\end{array}$} & \multirow[t]{2}{*}{ Se } & \multirow[t]{2}{*}{ Spe } & \multirow[t]{2}{*}{ AUC (95\% Cl) } & \multirow[t]{2}{*}{$\mathrm{P}$} & \multirow{2}{*}{$\begin{array}{c}\text { Difference value } \\
\quad(95 \% \mathrm{Cl}, \%)\end{array}$} & \multirow[t]{2}{*}{$\mathrm{P}$} & \multirow[t]{2}{*}{ Kappa $(95 \%$ Cl) } \\
\hline & & Sensitive & Resistant & & & & & & & \\
\hline \multirow{2}{*}{$\begin{array}{l}\text { DNA } \\
\text { microarray }\end{array}$} & Sensitive & 559 & 66 & 0.73 & 0.97 & $0.85(0.82-0.87)$ & $<0.001$ & $6.06(3.95-8.17)$ & $<0.001$ & $0.75(0.70-0.80)$ \\
\hline & Resistant & 16 & 184 & & & & & & & \\
\hline
\end{tabular}

AUC, area under the curve; $\mathrm{Cl}$, confidential interval; INH, isoniazid; Se, sensitivity; Spe, specificity.

M. tuberculosis resistant to RFP and INH, with 85 of 110 (sensitivity: $77.3 \%$ ) strains resistant to INH and 22 of 30 (sensitivity: $73.3 \%$ ) strains sensitive to INH were detected. In a study by Skotnikova et al. (23) in 2003, an attempt was made to analyze $\operatorname{rpoB}, k a t G$, inb $A$, and oxyR/abpC gene mutations in RFP- and INH-resistant $M$. tuberculosis using biochip technology. Thereafter, a large number of studies have detected INH-resistant $M$. tuberculosis with DNA microarray (16,24-27). Zhang et al. (28) assessed the performance of the CapitalBio DNA microarray in the detection of INH resistance in spinal tuberculosis using the BACT/MGIT 960 liquid clture results as referece standard. The microarray had a sensitivity of $80.0 \%$ and a specificity of $91.0 \%$ for INH resistance, and the mean turnaround time was 5.8 (range, 4-9) hours. A meta-analysis conducted in 2014 showed that the overall sensitivity of DNA microarray for detecting INH resistance was 0.79 (95\% CI: $0.77-0.81$ ), the overall specificity was 0.94 (95\% CI: $0.93-0.95)$, and the AUC was 0.86 (21). The sensitivity and specificity of DNA microarray detection of INH resistance in our current study were consistent with the data from previous studies. In addition, the AUC was greater than 0.75 , a generally accepted cutoff value (29), which indicates good diagnostic performance of the DNA microarray. Recently, Zhang et al. (22) tested 2,143 sputum specimens from previously treated patients in Changchun, China, for RFP and INH resistance-related gene mutations by using the BACT/MGIT 960 culture system and the CapitalBio DNA microarray (CapitalBio, China): the sensitivity and specificity of the DNA microarray for INH resistance were $79.9 \%$ and $99.6 \%$, respectively. The same chip was used in our current study, and a similar sensitivity (73\%) and specificity (97\%) in detecting INH resistance were observed.

\section{Limitations in research}

Some limitations to our study should be noted. First, the retrospective design and the exclusion of patients with missing data might have led to bias. Second, our study was carried in a single center with a relatively small sample size, which might have limited the applicability of the study's conclusions.

In summary, DNA microarray is a rapid, accurate, and practical method for detecting drug-resistant TB in clinical settings. Traditional culture methods are time-consuming and have high technical laboratory requirements. In contrast, DNA microarray enables the early and rapid detection of drug-resistant mutations, which is particularly important for effective treatment of drug-resistant TB and the prevention and control of TB transmission. Future research should focus on improving the ability of detecting drug-resistant mutations in M. tuberculosis and establishing and optimizing surveillance systems, for which the CapitalBio DNA microarray may serve a critical role.

\section{Acknowledgments}

Funding: This study was supported by the national science and technology major project in the 13th Five-year Plan Period (Grant number: 2018ZX10103001).

\section{Footnote}

Reporting Checklist: The authors have completed the STARD reporting checklist. Available at https://dx.doi. org/10.21037/jtd-21-913

Data Sharing Statement: Available at https://dx.doi. org/10.21037/jtd-21-913

Conflicts of Interest: All authors have completed the ICMJE uniform disclosure form (available at https://dx.doi. org/10.21037/jtd-21-913). The authors have no conflicts of interest to declare.

Ethical Statement: The authors are accountable for all 
aspects of the work in ensuring that questions related to the accuracy or integrity of any part of the work are appropriately investigated and resolved. All procedures performed in this study involving human participants were in accordance with the Declaration of Helsinki (as revised in 2013). This study was approved by the institutional review board of our hospital (Ethical approval document number: KYXM-2019-056-01). All patients signed the informed consent forms.

Open Access Statement: This is an Open Access article distributed in accordance with the Creative Commons Attribution-NonCommercial-NoDerivs 4.0 International License (CC BY-NC-ND 4.0), which permits the noncommercial replication and distribution of the article with the strict proviso that no changes or edits are made and the original work is properly cited (including links to both the formal publication through the relevant DOI and the license). See: https://creativecommons.org/licenses/by-nc-nd/4.0/.

\section{References}

1. Floyd K, Glaziou P, Zumla A, et al. The global tuberculosis epidemic and progress in care, prevention, and research: an overview in year 3 of the End TB era. Lancet Respir Med 2018;6:299-314.

2. Unissa AN, Subbian S, Hanna LE, et al. Overview on mechanisms of isoniazid action and resistance in Mycobacterium tuberculosis. Infect Genet Evol 2016;45:474-92.

3. Koch A, Mizrahi V. Mycobacterium tuberculosis. Trends Microbiol 2018;26:555-6.

4. WHO Guidelines Approved by the Guidelines Review Committee. WHO consolidated guidelines on drugresistant tuberculosis treatment. Geneva: World Health Organization (C) World Health Organization 2019.

5. Van Deun A, Decroo T, Tahseen S, et al. World Health Organization 2018 treatment guidelines for rifampicinresistant tuberculosis: uncertainty, potential risks and the way forward. Int J Antimicrob Agents 2020;55:105822.

6. Hameed HMA, Tan Y, Islam MM, et al. Phenotypic and genotypic characterization of levofloxacin- and moxifloxacin-resistant Mycobacterium tuberculosis clinical isolates in southern China. J Thorac Dis 2019;11:4613-25.

7. Small PM, Pai M. Tuberculosis diagnosis--time for a game change. N Engl J Med 2010;363:1070-1.

8. Kohli M, Schiller I, Dendukuri N, et al. Xpert(@) MTB/RFP assay for extrapulmonary tuberculosis and rifampicin resistance. Cochrane Database Syst Rev 2018;8:CD012768.

9. Nathavitharana RR, Cudahy PG, Schumacher SG, et al. Accuracy of line probe assays for the diagnosis of pulmonary and multidrug-resistant tuberculosis: a systematic review and meta-analysis. Eur Respir J 2017;49:1601075.

10. Marzancola MG, Sedighi A, Li PC. DNA microarraybased diagnostics. Methods Mol Biol 2016;1368:161-78.

11. Guo Y, Zhou Y, Wang C, et al. Rapid, accurate determination of multidrug resistance in $\mathrm{M}$. tuberculosis isolates and sputum using a biochip system. Int J Tuberc Lung Dis 2009;13:914-20.

12. Huang WL, Hsu ZJ, Chang TC, et al. Rapid and accurate detection of rifampin and isoniazid-resistant Mycobacterium tuberculosis using an oligonucleotide array. Clin Microbiol Infect 2014;20:O542-9.

13. Zhao Yanlin, Liu Zhimin. Standardized operation and network construction of tuberculosis laboratory. Beijing People's Medical Publishing House, 2013.

14. Head SR, Parikh K, Rogers YH, et al. Solid-phase sequence scanning for drug resistance detection in tuberculosis. Mol Cell Probes 1999;13:81-7.

15. Jing F, Hu Z, Sun Y. Rapid detection of Mycobacterium tuberculosis resistance to rifampicin using DNA chip. Zhonghua Jie He He Hu Xi Za Zhi 2001;24:551-4.

16. Aragón LM, Navarro F, Heiser V, et al. Rapid detection of specific gene mutations associated with isoniazid or RFPampicin resistance in Mycobacterium tuberculosis clinical isolates using non-fluorescent low-density DNA microarrays. J Antimicrob Chemother 2006;57:825-31.

17. Cui ZL, Jing FX, Hu ZY, et al. The use of gene chip in detecting Mycobacterium tuberculosis resistant to rifampicin and isoniazid. Zhonghua Jie $\mathrm{He} \mathrm{He} \mathrm{Hu} \mathrm{Xi} \mathrm{Za}$ Zhi 2004;27:439-41.

18. Sánchez-Cabral O, Santillán-Díaz C, Flores-Bello ÁP, et al. GeneXpert ${ }^{\circledR} M T B / R I F$ assay with transbronchial lung cryobiopsy for Mycobacterium tuberculosis diagnosis. Ann Transl Med 2020;8:351.

19. Pang $\mathrm{Y}, \mathrm{Xia} \mathrm{H}$, Zhang $\mathrm{Z}$, et al. Multicenter evaluation of genechip for detection of multidrug-resistant Mycobacterium tuberculosis. J Clin Microbiol 2013;51:1707-13.

20. Spitaleri A, Ghodousi A, Miotto P, et al. Whole genome sequencing in Mycobacterium tuberculosis. Ann Transl Med 2019;7:S197.

21. Geng H, Li Y, Li X, et al. Evaluation of genechip for detecting isoniazid-and rifampicin-resistance of 
Mycobacterium tuberculosis in China: a Meta-analysis. Chin J Infect Dis 2014;32:357-63.

22. Zhang MJ, Ren WZ, Sun XJ, et al. GeneChip analysis of resistant Mycobacterium tuberculosis with previously treated tuberculosis in Changchun. BMC Infect Dis 2018;18:234.

23. Skotnikova OI, Nosova EY, Markova OV, et al. Typing of Mycobacterium tuberculosis strains resistant to RFPampicin and isoniazid by molecular biological methods. Bull Exp Biol Med 2003;136:273-5.

24. Brown TJ, Herrera-Leon L, Anthony RM, et al. The use of macroarrays for the identification of MDR Mycobacterium tuberculosis. J Microbiol Methods 2006;65:294-300.

25. Kim SY, Park YJ, Song E, et al. Evaluation of the CombiChip Mycobacteria Drug-Resistance detection DNA chip for identifying mutations associated with resistance to isoniazid and Rifampicin in

Cite this article as: Sun B, Sun Y. Diagnostic performance of DNA microarray for detecting rifampicin and isoniazid resistance in Mycobacterium tuberculosis. J Thorac Dis 2021;13(7):4448-4454. doi: 10.21037/jtd-21-913
Mycobacterium tuberculosis. Diagn Microbiol Infect Dis 2006;54:203-10.

26. Isakova ZhT. Practical value of the TB-biochip MDR test system in the rapid identification of multidrug-resistant $M$. tuberculosis strains. Klin Lab Diagn 2009;(2):50-1.

27. Yao C, Zhu T, Li Y, et al. Detection of rpoB, katG and inhA gene mutations in Mycobacterium tuberculosis clinical isolates from Chongqing as determined by microarray. Clin Microbiol Infect 2010;16:1639-43.

28. Zhang Z, Li L, Luo F, et al. Rapid and accurate detection of RMP- and INH- resistant Mycobacterium tuberculosis in spinal tuberculosis specimens by CapitalBio ${ }^{\mathrm{TM}} \mathrm{DNA}$ microarray: a prospective validation study. BMC Infect Dis 2012;12:303.

29. Alba AC, Agoritsas T, Walsh M, et al. Discrimination and calibration of clinical prediction models: Users' guides to the medical literature. JAMA 2017;318:1377-84. 